\title{
Correction to: Genome-wide association study identifies new loci for albuminuria in the Japanese population
}

\author{
Hiroshi Okuda ${ }^{1,2,3} \cdot$ Koji Okamoto $^{2,3} \cdot$ Michiaki Abe $^{1,2,3} \cdot$ Kota Ishizawa $^{1,2} \cdot$ Satoshi Makino ${ }^{2} \cdot$ Osamu Tanabe ${ }^{2,4}$. \\ Junichi Sugawara ${ }^{2} \cdot$ Atsushi Hozawa $^{2} \cdot \mathrm{Kozo}_{\text {Tanno }}{ }^{5} \cdot$ Makoto Sasaki $^{5} \cdot$ Gen Tamiya $^{2,6}$ - Masayuki Yamamoto ${ }^{2}$. \\ Sadayoshi Ito ${ }^{2,3} \cdot$ Tadashi Ishii $^{1,2}$
}

Published online: 27 March 2021

(c) The Author(s) 2021

\section{Correction to: Clinical and Experimental Nephrology (2020) 24:696-704 https://doi.org/10.1007/s10157-020-01884-x}

The article "Genome-wide association study identifies new loci for albuminuria in the Japanese population", written by Hiroshi Okuda - Koji Okamoto - Michiaki Abe · Kota Ishizawa $\cdot$ Satoshi Makino $\cdot$ Osamu Tanabe $\cdot$ Junichi Sugawara - Atsushi Hozawa - Kozo Tanno - Makoto Sasaki . Gen Tamiya · Masayuki Yamamoto - Sadayoshi Ito and Tadashi Ishii was originally published Online First without Open Access. After publication in volume 24, issue 8, pages 696-704 the author decided to opt for Open Choice

The original article can be found online at https://doi.org/10.1007/ s10157-020-01884-x.

The original article has been corrected.

Koji Okamoto

okamoto5-tky@umin.ac.jp

1 Department of Education and Support for Regional Medicine, Tohoku University Hospital, 1-1 Seiryo-machi, Aoba-ku, Sendai, Miyagi 980-8574, Japan

2 Tohoku Medical Megabank Organization, Tohoku University, 2-1 Seiryo-machi, Aoba-ku, Sendai, Miyagi 980-8573, Japan

3 Department of Nephrology, Endocrinology and Vascular Medicine, Graduate School of Medicine, Tohoku University, 1-1 Seiryo-machi, Aoba-ku, Sendai, Miyagi 980-8574, Japan

4 Radiation Effects Research Foundation, 5-2 Hijiyama Park, Minami-ku, Hiroshima, Hiroshima 732-0815, Japan

5 Iwate Tohoku Medical Megabank Organization, Iwate Medical University, 1-1-1 Idaidori, Yahaba-cho, Shiwa-gun, Iwate 028-3694, Japan

6 RIKEN Center for Advanced Intelligence Project Nihonbashi, 1-chome Mitsui Bldg. 15F, 1-4-1 Nihonbashi, Chuo-ku, Tokyo 103-0027, Japan and to make the article an Open Access publication. Therefore, the copyright of the article has been changed to $(9)$ The Author(s) 2021 and the article is forthwith distributed under the terms of the Creative Commons Attribution 4.0 International License (https://creativecommons.org/licenses/by/4. 0/), which permits use, sharing, adaptation, distribution and reproduction in any medium or format, as long as you give appropriate credit to the original author(s) and the source, provide a link to the Creative Commons licence, and indicate if changes were made. The original article has been corrected.

Open Access This article is licensed under a Creative Commons Attribution 4.0 International License, which permits use, sharing, adaptation, distribution and reproduction in any medium or format, as long as you give appropriate credit to the original author(s) and the source, provide a link to the Creative Commons licence, and indicate if changes were made. The images or other third party material in this article are included in the article's Creative Commons licence, unless indicated otherwise in a credit line to the material. If material is not included in the article's Creative Commons licence and your intended use is not permitted by statutory regulation or exceeds the permitted use, you will need to obtain permission directly from the copyright holder. To view a copy of this licence, visit http://creativecommons.org/licenses/by/4.0/.

Publisher's Note Springer Nature remains neutral with regard to jurisdictional claims in published maps and institutional affiliations. 